\title{
Measurement of cognitive ability and thinking level of 10- and 13- year-old football players with football-specific tasks
}

\author{
István Kun, Laszlo Toth \\ Faculty of Physical Education and Sport Science, Semmelweis University, Budapest, Hungary
}

\begin{abstract}
Summary
Study aim: To assess whether in a special area, such as football, formal thinking may appear as early as at the age of 10 years.

Material and methods: In total 50 children divided into three groups took part in the study: 10-year-old football players from the Premier League Team - level 1 (Group 1; $\mathrm{n}=22$ ), 10-year-old football players from the Football League Team - level 3 (Group 2; $\mathrm{n}=13$ ) and 13-year-old football players from the Premier League Team - level 1 (Group 3; $\mathrm{n}=15$ ). With the help of specific motor tests, the kinetic memory, level of thinking and technical level were assessed.

Results: The 10-year-old children representing lower levels of football proficiency (Group 2) were significantly $(\mathrm{p}<0.05)$ inferior to their mates from the Premier League in both the level of thinking as well as in kinetic memory. No significant differences were found between members of Group 1 and Group 3 in any of the studied variables.

Conclusions: The results support the thesis that 10-year-old children are able to use formal thinking in a particular area, such as football. To be aware of this would be of great importance to those experts who deal with selection and talent identification.
\end{abstract}

\section{Key words: Football - Developmental psychology - Thinking level - Cognitive ability}

\section{Introduction}

According to Bloomfield [3], sport experts and coaches from many relatively small countries think that talent identification is essential for their programme to develop the sport. In these countries, the question arises whether there are enough people to reach the elite levels seen in countries with large populations selecting by means of choosing.

Peltola [19] claims that competition itself is the best way to identify talent; it is during competition that one can register the best performances and talent fulfils itself in its own chosen branch of sport. Several authors mention that regular and systematic talent identification is part of sports from all over the world $[1,11,14]$.

In our opinion, it is necessary in Hungary to have accurate and scientifically established football talent identification. The size of the country, the number of its people, and the number of footballers cannot allow sport leaders of football to ignore the fact that each and every child should take a place that is appropriate for his/her knowledge. It means that the most talented children should be trained by clubs having the best circumstances and by the best coaches, experts, and teachers.

Coaches and scientists have argued that perceptualcognitive skills play a crucial role in sports performance, particularly at the highest levels. It is widely accepted that skilled performers are not endowed with superior visual skills per se, but rather enhanced cognitive knowledge bases that enable them to pick up and interpret perceptual information more effectively than their less skilled counterparts $[13,26]$.

Based on the topics discussed above, it is clear that countries which play a leading role in football place great emphasis upon the standard of thinking when selecting the players. Helsen et al. [13] examined differences in tactical decision-making skills between experienced and intermediate-level adult football players. Participants watched open and closed (i.e., set plays) offensive football simulations and were asked to respond quickly and accurately. The experienced players were faster and more accurate in responding and employed fewer fixations of shorter duration when compared with their less skilled counterparts. Ward et al. [23] assessed the role of expectations (i.e., situational probabilities) in decision-making by requiring young football players to view filmed sequences taken from competitive matches, and then highlight the key players in a good position to receive the ball. The results revealed that elite football players demonstrated superior perceptual-cognitive skills compared to their sub-elite counterparts; these differences were evident 
as early as 9 years of age. Vaeyens et al [21] in their study examined the mechanisms underlying decision-making skill in football. They analysed differences in decisionmaking skill and visual search behaviour using simulations involving different microstates of the game and groups of adolescents matched by age and playing experience. It was shown that the visual search behaviour employed during decision-making varies as a function of playing experience, skill level, and the unique constraints of the task. The number of players involved and the relative proportion of offensive to defensive players all play a part in constraining the emergent search behaviour. They provided evidence that confirmed that an increase in the number of players and a greater relative proportion of offensive to defensive players changed the perceptual and cognitive demands of the task. The measures employed were able to successfully discriminate between football players and non-players, and more importantly, between elite and sub-elite players and their regional counterparts.

In the golden age of the Hungarian football this was typical of the Hungarians and our training system as well. This is why it is necessary and timely to establish a unified selecting system that focuses on standards of thinking as well as physical abilities.

By creating a series of training practice exercises, we intended to test the standard of thinking (which can be an essential element of selection) during the game. The level of technical knowledge hinders the possibilities for teamwork, the signs of which become visible at the very early age. Consequently, those children who can think at a higher level than others can learn the special motions, techniques, and tactics more easily and quickly $[18,20]$. The aim of this survey was thus to assess whether in a special field, like football, formal thinking may appear as early as at the age of 10 . To answer that question the following hypotheses were tested: (1) the level of thinking differs between 10-year-old children representing different levels of football proficiency, (2) the level of thinking differs between 10-year-old and 13-year-old children representing different levels of football proficiency, (3) 10-year-old and 13-year-old children representing the same levels of football proficiency demonstrate the same levels of thinking, (4) children demonstrate the same technical level irrespectively of their age and level of football proficiency.

\section{Material and Methods}

In total 50 children divided into three groups took part in the study: 10-year-old football players from the Premier League Team - level 1 (Group 1; $\mathrm{n}=22$ ), 10-year-old football players from the Football League Team - level 3 (Group 2; $\mathrm{n}=13$ ) and 13-year-old football players from
Premier League Team - level 1 (Group 3; $\mathrm{n}=15$ ). The survey was conducted on the pitches and laboratories of TF (Semmelweis University Faculty of Physical Education and Sport Sciences, Budapest, Hungary). With the help of motor tests, children's kinetic memory, level of thinking, and technical level were measured; the study was approved by the local Committee of Ethics.

Level of thinking (cogitation) - a task in which the presence of concrete or formal thinking is measured was recorded by a video camera. Nine direction-buoys were placed at an equal distance on a circle with a diameter of 10 meters. Eight children were standing by the buoys - one buoy was left free. One child had the ball; he had to pass it without stopping it to any of his team-mates other than the one standing next to him. Right after the pass he had to run to the buoy left free. Those who solved the task successfully could pass accurately with one contact and then leave towards the buoy in time [5]. With the help of the recording, the task was analysed according to the following criteria: passing accuracy; leaving for the good place; and leaving his position in time.

Technical level - a bench of 3 meters was leant against the wall: the top surface, where one usually sits, became the area to score onto. A line was painted 3 meters from the scoring area and in 60 seconds players had to pass the ball to that surface as many times as they could.

Kinetic memory: a buoy was placed one meter from the post of a handball goal. From a distance of 6 meters, they had to shoot the ball between the buoy and the post 5 times with eyes open and 5 times blindfolded [12].

Statistical analysis were conducted according Knapp's procedure [15]; to compare the results, a 5-level scale for the basic data was created. Then, these data were analysed with the use of the Kruskal-Wallis test, followed by the Tukey-b test. SPSS was used in data analyses; the level of $\mathrm{p}<0.05$ was considered significant.

\section{Results}

The results of the study are presented in Table 1. No significant differences between groups were noted for the task measuring technical level $\left(\mathrm{Chi}^{2}=1.7 ; \mathrm{p}=0.432\right)$ while these for the kinetic memory and the level of thinking the differences proved to be significant $\left(\mathrm{Chi}^{2}=16.7 ; \mathrm{p}<0.001\right.$ and $\mathrm{Chi}^{2}=17.6 ; \mathrm{p}<0.001$, respectively).

The results of the post hoc analyses show the 10-yearold children representing lower levels of football proficiency (Group 2) were significantly $(p<0.05)$ inferior to their mates from Premier League in both, level of thinking as well as in kinetic memory, while in any of the studied variables no significant differences were found between the younger (Group 1) and older (Group 3) football players from the Premier League (Table 1). 
Table1. Mean $( \pm \mathrm{SD})$ values of kinetic memory, level of thinking, and technical level recorded in young football players

\begin{tabular}{lccc}
\hline Variable & $\begin{array}{l}\text { Group 1 } \\
(\mathrm{n}=22)\end{array}$ & $\begin{array}{c}\text { Group 2 } \\
(\mathrm{n}=13)\end{array}$ & $\begin{array}{l}\text { Group 3 } \\
(\mathrm{n}=15)\end{array}$ \\
\hline Kinetic memory & $3.18 \pm 0.85$ & $2.23 \pm 0.44^{*}$ & $3.53 \pm 0.83$ \\
Level of thinking & $4.14 \pm 1.04$ & $2.77 \pm 0.60^{*}$ & $4.20 \pm 0.68$ \\
Technical level & $4.27 \pm 0.70$ & $4.00 \pm 0.82$ & $4.07 \pm 0.46$ \\
\hline
\end{tabular}

Legend: Group 1 - 10-year-old football players from the Premier League Team - level 1; Group 2 - 10-year-old football players from the Football League Team - level 3; Group 3 - 13-year-old football players from Premier League Team - level 1; * Significantly less than in other groups

\section{Discussion}

The special movements of football require special ways of thinking, the presence of which could and should be a filter when selecting players. According to Williams et al. [24], to determine which child has poor or good abilities concerning decision-making specific to football is possible as early as at the ages of 7-9 years. Ward et al. [23] suppose that the following processes take place in a player during a situation in the game: the player realizes the situation with the help of his perceptual abilities, he analyses it using his cognitive abilities, then executes his decision through his technical and kinetic abilities. Finally, using his visual abilities again, he collects information about the effect and the correctness of his action. In their opinion, the perception - decision-making - execution circle plays the most important part in recognizing the talented persons and selecting them. Apart from the laboratory studies and researches, they try to put their methods of measuring into practice and examine players through exercises that are designed to be performed during training sessions [9].

The child can only execute the task measuring the level of thinking perfectly if he creates a plan (at the very moment he notices and senses the ball heading towards him) about what to do next, to whom he shall pass the ball, and where he shall run after the pass. Making plans is one of the results of formal thinking $[4,20]$. The child can only execute the task perfectly if he recognizes the rule. Sensing where the ball comes from and where the empty area on the pitch is, is not enough; they have to know the rule. The rule is the following: they have to run and occupy the place of the person from whom the ball came, because there is the empty area on the pitch, since that is the place from where their fellow player had run away. If he does not know the rule he only notices where the empty buoy is and this is the direction he will head to after the pass (which means he can only react to concrete things) and he will notice only during running that his fellow player has already taken that place. In this moment he may try to change directions and search for an empty buoy and run towards it or continue to run to the original buoy in spite of the fact that his fellow player is standing there. One of the criterion of formal thinking is that children can imagine those things that have not happened yet. They order, classify, group the information they perceive, and thus they can understand the connections between them [6]. The young player who applies formal thinking - that is, in a particular situation analyse a particular moment of the game - can observe the connection that by the time he receives and then passes the ball - that is, when he has to run to the free buoy - the player who passed the ball him reaches that buoy that was free at the moment of the pass. Therefore, the player who received and passed the ball has to run to the buoy that has just become free [2]. Consequently, after sorting the perceived information the player can understand the connections and notices that the player who passes him the ball will run to the free buoy. Furthermore, he could also notice that the buoy - which the player who passed him the ball just left - will become free. In other words, the player can predict what will happen according to the perceived information [17].

Regarding the technical level, there is no difference among the three groups, which means that the execution of the task measuring the level of thinking does not depend on the technical standard of the players. The technical elements are the basis of football, which are taught everywhere independent of the quality and class of the team the children are learning to play football. In spite of this, there is a difference between the 10-year-olds from Group2 (aged 10 years) and Group1 (aged 10 years), which resulted in Group1 (aged 10 years) scoring more goals than Group2 (aged 10 years) during the matches. If there is no technical difference, still, there is some difference regarding the quality of the playing, what can be the root of this disparity? The results of the survey show that the truth can be found in the standard of thinking.

According to Knapp's [16] theory, kinetics can only be used from the third stage (the stage of refinement, the foundation of movement coordination). It seems to be clear that the received results show us the differences between the 10-year-old children and the 13-year-old 
children, and the existence and presence of this difference stems from the normal pace of children's natural development. The data also show that the task measuring the thinking actually measures the thinking during the game; that is to say, the execution of this task does not depend on the level of technical skills. The technical element is considered to be those movements that belong to the repertoire of a particular sport. Technique is the practical and efficient execution of these technical elements in a game situation. Knowing a technical element does not mean that a player can use it during the match; that is, a technical element does not turn into automatically technique. Sixty percent of traditional football technical elements are practiced. Besides this fact, the vast majority of the players would not be called "skilled players". In order to apply technical elements during a football match, gamerelated thinking is necessary. This game-related thinking transforms technical elements into technique [22]. Furthermore, the data can prove that children may start to use formal thinking during the game even at the age of 10 years. The presence of formal operational thinking at an early age can be an important factor when selecting players in football [8]. As a result, those children who use formal thinking have an advantage in learning movements, as opposed to the others who use only the concrete operations. These children learn the tactical-cognitive abilities faster; therefore, they can learn more about football than their fellow players $[7,10]$ who only use formal thinking. The main difference between amateur and professional teams is whether or not simple technical elements are converted into technique during training sessions. Amateur players are only able to react to the actions during the game, and thus the speed of their play is slow. On the contrary, professional players continuously analyse the match situations and bear in mind those elements that have yet to occur. Therefore, their play is faster and continuous [25].

Based on the results it can be concluded that 10-yearold children can use formal thinking in a particular field, such as football. To be aware of these factors would be of great importance for those experts who deal with selection [27]. Certainly, game-related thinking is a complex process, and our research cannot fully measure its complexity. This complexity could be the reason to the observed high dispersion of the data. Other studies are in progress, and we endeavour to measure, examine, and understand in deeper levels this complex issue. In order to be sure that the exercise - which was presented previously - measures the existence of formal thinking, other measurements should be fulfilled. Additionally, more accurate data could be presented about the actual movements, passing, and decision-making of the players if the abovementioned exercise was recorded and analysed with a match analysis system. What is more, in order to prove the accuracy and authenticity of the measurement, it would be useful to assess the level of thinking, technical skills, and kinetic memory among the children who do not play football at all.

\section{References}

1. Baur J. (1986) Talent Identification and Development in Sport: An Interim Evaluation, Part 1. Unpublished translation - (Australian Institute of Sport, Belconnen), 1988, 1-26.

2. Bell-Walker J., A.M.Williams (2008) The effect of memory recall on perceptual-cognitive skill in elite soccer: Development of long term working memory. In: T.Reilly, F.Korkusuz, E.Ergen (eds): Science and Football. VI. Taylor and Francis, London. pp. 340-343.

3. Bloomfield J., T.R.Ackland, E.L.Bruce (1994) Applied Anatomy and Biomechanics in Sport. Blackwell Scientific Publ.

4. Cabrini M. (1999) The Psychology of Soccer. Reedswain INC. Spring City Pennsylvania.

5. Caruso A. (1996) Soccer Coaching Ages 5 to 12. Reedswan INC. Spring City Pennsylvania.

6. Chi M. (1978) Knowledge structures and memory development. In: R.Siegler (ed.) Children's Thinking: What develops? Hillsdale, NJ: Lawrencw Elbaum, pp. 73-96.

7. D’Ottavio S. (2003) La presentacione del giovanile calciatore. Societá Stampa Sportiva, Roma.

8. D'Ottavio S. (2004) Guida technica per le ccuole di calcio. F. I. G. C. - Settore giovanile e scolastico.

9. Fenoglio R. (2003) The Manchester United 4 v 4 pilot scheme for U9s. FA Coaches Assoc.J., 6 (3):18-19.

10. Ford P.R., P.Ward, N.J.Hodges, A.M.Williams (2009) The role of deliberate practice and play in career progression in sport: The early engagement hypothesis. High Abil.Stud., 20:65-75.

11. Hahn A. (1990) Identification and selection of talent in Australian rowing. Excel, 6 (3):5-11.

12. Hirtz P. (1985) Koordinative Fähigkeiten im Schulsport. Volk und Wissen Volkseigner Verlag. Berlin.

13. Helsen W.F., J.L. Starkes (1999) A multidimensional approach to skilled perception and performance in sport. Appl. Cognit.Psychol., 13:1-27.

14. Hoare D. (1995) Talent Search. The National Talent Identification and Development Program, 13 (2):10-12.

15. Knapp B. (1963) Skill in sport. In: L.Killik (ed.) Basic Elements of Motor Learning. Sportpropaganda, MTS-OT, Budapest.

16. Knapp B. (1989) Basic Questions of Motor Learning. MTSOT, 8:10-12.

17. Kun I., L.Toth (2010) The correlation of differential learning and the stage of cognitive development in football trough a game of three against one. Int.Q.Sport Sci., 2:27-42.

18. Nunes T., A.D.Schliemann, D.W.Carraher (1993) Street Mathematics and School Mathematics. New York, Cambridge University Press.

19. Peltola E. (1992) Talent Identification. New Stud.Athl., 7 (3):7-12.

20. Piaget J. (1999) Psychology of Children. In Hungarian. Osiris Budapest.

21. Vaeyens R., M.Lenoir, A.M.Williams, L.Mazyn, R.M.Philippaerts (2007) The effects of task constraints on visual search behavior and decision-making skill in youth soccer players. J.Sport Exerc.Psychol., 29:147-169.

22. Ward P., A.M.Williams, (2003) Perceptual and cognitive skill development in soccer: The multidimensional nature of expert performance. J.Sport Exerc.Psychol., 25:93-111. 
23. Ward P., N.J.Hodges, A.M.Williams, J.L.Starkes, (2004) Deliberate practice and expert performance: Defining the path to excellence. In: A.M.Williams, N.J.Hodges (eds.) Skill Acquisition in Sport: Research, Theory and Practice. London: Routledge, pp. $231-258$.

24. Williams A.M., K.Davids, L.Burwitz, J.Williams (1993) Cognitive knowledge and soccer performance. Percept.Motor Skills, 76:579-594.

25. Williams A.M., K.Davids (1998) Visual search strategy, selective attention, and expertise in soccer. Res.Q.Exerc.Sport, 69:111-128
26. Williams A.M., A.Grant (1999) Training perceptual skill in sport. Int.J.Sport Psychol., 30:194-220.

27. Williams A.M., T.Reilly (2000) Talent identification and development in soccer. J.Sport Sci., 5:657-670.

\section{Received 20.01.2012 \\ Accepted 18.06.2012}

(c) University of Physical Education, Warsaw, Poland 